\title{
Effect of partial pancreatectomy on diabetic status in BALB/c mice
}

\author{
A A Hardikar ${ }^{1}$, M S Karandikar ${ }^{2}$ and R R Bhonde ${ }^{1}$ \\ ${ }^{1}$ Tissue Engineering and Banking Laboratory, National Centre for Cell Science, NCCS Complex, Ganeshkhind, Pune 411007, Maharashtra, India \\ ${ }^{2}$ Department of Physiology, B J Medical College, Pune 411004, India \\ (Requests for offprints should be addressed to R R Bhonde)
}

\begin{abstract}
Pancreatic regeneration after pancreatectomy has been well documented in animal models. However, the phenomenon of pancreatic regeneration in diabetes has not been exploited as yet. We report here the restoration of euglycaemic status in streptozotocin (STZ)-induced diabetic BALB/c mice, after 50\% pancreatectomy. We observed that, after pancreatectomy, STZ-diabetic mice showed a rapid improvement in glycaemic status, starting from the 8th postoperative day, and remained normoglycaemic throughout a 90-day follow-up study. STZinduced diabetic and control non-diabetic BALB/c mice underwent pancreatectomy and were monitored regularly for changes in body weight, plasma glucose and serum insulin concentrations and histological status of the pancreas. All the pancreatectomised animals showed euglycaemic status from about 20 days after operation, whereas a majority (around 70\%) of the diabetic, sham-
\end{abstract}

operated animals died of sustained hyperglycaemia by 20-30 days after operation. Examination of the regenerating pancreas indicated nesidioblastotic activity and supported the theory of a ductal origin of islet stem cells. Islets isolated from the regenerating pancreas showed a progressive increase in islet area $\left(1227.9 \pm 173.2 \mu \mathrm{m}^{2}\right.$ on day 5 compared with $2473 \cdot 8 \pm 242 \cdot 0 \mu \mathrm{m}^{2}$ by day 20 ). The increment in insulin concentrations and subsequent decrement in glycaemia of the diabetic pancreatectomised animals indicate islet neogenesis occurring after the operative insult, leading to a normoglycaemic status, probably recapitulating ontogeny. We have shown that induction of a regenerative stimulus (pancreatectomy) in conditions of STZ-induced diabetes may trigger pancreatic regenerative processes, thereby restoring a functional pancreas, in STZ-diabetic mice.

Journal of Endocrinology (1999) 162, 189-195

\section{Introduction}

Endocrine and exocrine pancreatic regeneration after pancreatectomy has been well documented in animal models (Bonner-Weir et al. 1993, Slack 1995), but pancreatic regeneration in diabetes has not been reported as yet. It is generally believed that the number of functionally intact $\beta$-cells in the islet organ is of decisive importance in the development, course and outcome of diabetes mellitus and also, possibly, for its reversal. A major complement of the $\beta$-cells in adults is established much earlier, during the neonatal period, when islet cells differentiate from primitive duct-like cells. The adult pancreatic $\beta$-cells are thus of a terminal nature and only about 3\% of the islet cells are capable of proliferation (Swenne 1983, Tanigawa et al. 1997). However, the factors controlling such nesidioblastotic/proliferative events remain largely unknown. It is therefore important to identify those factors that determine pancreatic $\beta$-cell proliferation and nesidioblastosis. Nesidioblastosis, or neogenesis of islets, in adult mammals has been debated for a long time and various sources of islet neogenesis have been proposed. Increase in pancreatic $\beta$-cell mass may result from mitotic proliferation of pre-existing islet cells, or islets may bud off from the ductal system of the pancreas (Slack 1995), arise from transformation of the acini into new islets, or may even be derived from the centro-acinar cells (Jindal et al. 1995). There is strong evidence that islet stem cells may exist in the pancreatic duct (Hellerstrom 1984, Bonner-Weir et al. 1993) and that these ductal epithelial cells may be switched into a proliferative/regenerative phase leading to nesidioblastosis. In mammals, organs such as the liver and pancreas are well known to inherit a strong regenerative potential; however, the process of regeneration has to be preceded by an operative insult that involves removal of a part of the entire organ (Michalopoulos \& DeFrances 1997). Pancreatectomy has already been established as a model of diabetes (Bonner-Weir et al. 1983), and substantial regeneration of both exocrine and endocrine pancreas after $90 \%$ pancreatectomy has been documented (BonnerWeir et al. 1993). However, attention has not been focused on regeneration of the diabetic pancreas. We carried out this study in an effort to understand the pancreatic regenerative processes in the diabetic condition. 


\section{Materials and Methods}

\section{Animals}

$\mathrm{BALB} / \mathrm{c}$ mice were studied in four groups: control/nondiabetic sham-operated (CS), diabetic sham-operated (DS), control/non-diabetic pancreatectomised (CPx) and diabetic pancreatectomised (DPx). All animals were obtained from an inbred population of $\mathrm{BALB} / \mathrm{c}$ mice at the animal house of National Centre for Cell Science, Pune, India. For the DPx and DS groups, 8-week-old $\mathrm{BALB} / \mathrm{c}$ mice (either sex) were rendered diabetic by an i.p. injection of streptozotocin (STZ; Sigma Chemical Co., St Louis, USA) in a dose of $200 \mathrm{mg} / \mathrm{kg}$ body weight (Bonner-Weir et al. 1993). STZ was reconstituted in chilled sodium citrate buffer $(\mathrm{pH} 4 \cdot 5)$ just before injection. STZ-diabetic animals showing frank diabetic status (fasting plasma glucose $>200 \mathrm{mg} / \mathrm{dl}$ ) for 2 weeks were taken for the study.

\section{Operative procedure}

Ten-week-old BALB/c mice of either sex were taken for the operative procedure. Animals were fasted overnight and anaesthetised by i.p. administration of sodium thiopentone (40 mg/kg body weight). Animals were operated on following the procedure of Bonner-Weir et al. (1983) with slight modifications: the entire splenic portion of the pancreas was removed, keeping the mesenteric pancreas intact. The incisions were sutured using absorbable 6-0 catgut sutures from Stericat Gutstrings, Delhi, India and autoclipper from Becton Dickinson (Mountain View, CA, USA). All animals (pancreatectomised and sham operated) received an i.p. injection of gentamycin $(3 \mathrm{mg} / \mathrm{kg}$ body weight), ampicillin and cloxacillin $(20 \mathrm{mg} / \mathrm{kg}$ body weight) and diclofenac sodium $(0.5 \mathrm{mg} / \mathrm{kg}$ body weight), for 3 days starting from the operative day, in addition to topical ointments (soframycin). In the case of sham operations, animals were anaesthetised as above, an incision was made and pancreata were handled as in the Px groups. Animals were then sutured as described earlier, without removal of the pancreas.

\section{Glucose and insulin estimations}

Plasma glucose was estimated by a glucose oxidase method using an Analox GM7 auto-analyser (Analox Instruments, London, UK), with calibration standards from Sigma (Poole, Dorset, UK). Serum insulin concentrations were measured by radioimmunoassay kit (Diagnostic Products Corporation, Los Angeles, CA, USA), using purified rat insulin standard (Novo Nordisk, Denmark; obtained as a gift from Prof. Claude Remacle, Université Catholique de Louvain, Louvain-la-Neuve, Belgium). Pancreatic insulin content was measured in pancreata collected in pre-chilled acid-ethanol (75\% absolute ethanol, 1.5\% $10 \mathrm{M} \mathrm{HCl}$ and distilled water to make up the volume), minced, sonicated and kept overnight at $-20{ }^{\circ} \mathrm{C}$ before the assay.

\section{Amylase estimations}

Circulating amylase concentrations were measured from serum samples collected at predetermined time points. Amylase was detected using a standard amylase detection kit from Beacon Diagnostics (Navsari, India).

\section{Histological procedures}

Pancreas from the pancreatectomised and sham-operated mice were taken from animals killed 15 days after the operative procedures, and fixed in 10\% buffered formaldehyde. Sections $7 \mu \mathrm{m}$ thick were taken on a rotary microtome (Reichert-Jung 2030 Biocut, Cambridge instruments $\mathrm{GmbH}$, Heidelberg, Germany) and stained with haematoxylin and eosin (HE) and light-green.

\section{Image quantification}

In order to quantify the pancreatic islet size, we isolated islets from animals in the DPx group at 5 and 20 days after pancreatectomy, following the procedure of Gotoh et al. (1985). Islets isolated from non-diabetic, sham-operated animals of the same age were taken as controls. In order to avoid a selection bias in islet size, pancreata from control and Px groups were processed for islet isolation in a single batch of experiments and islet isolation was carried out under perfectly identical conditions. Islets were suspended in RPMI 1640 medium with 10\% FCS, handpicked, counted and then taken for quantification. Computations were done on a Kontron image analysis system (Kontron Elektronik $\mathrm{GmbH}$, München, Germany) connected to a Ziess microscope. Islets were observed, images captured with a Variocam, Germany PCO CCD imaging camera and quantifications of islet size were made using the Kontron Image analysis software version $2 \cdot 04$.

\section{Statistical analysis}

Computations were performed using Jandel Scientific Sigma-stat statistical package (version 4 for Windows 95). Results are expressed as means \pm S.E.M. for normally distributed data or median and interquartile range when data were not normally distributed. Differences between groups were tested by Mann-Whitney test and serial changes in plasma glucose and serum insulin concentrations by paired $t$-test or Wilcoxon test as appropriate.

\section{Results}

The CS group (Fig. 1) showed an increase in body weight $(22 \cdot 3 \pm 0 \cdot 3$ to $24 \cdot 6 \pm 0 \cdot 5 \mathrm{~g})$ during the period of study. 


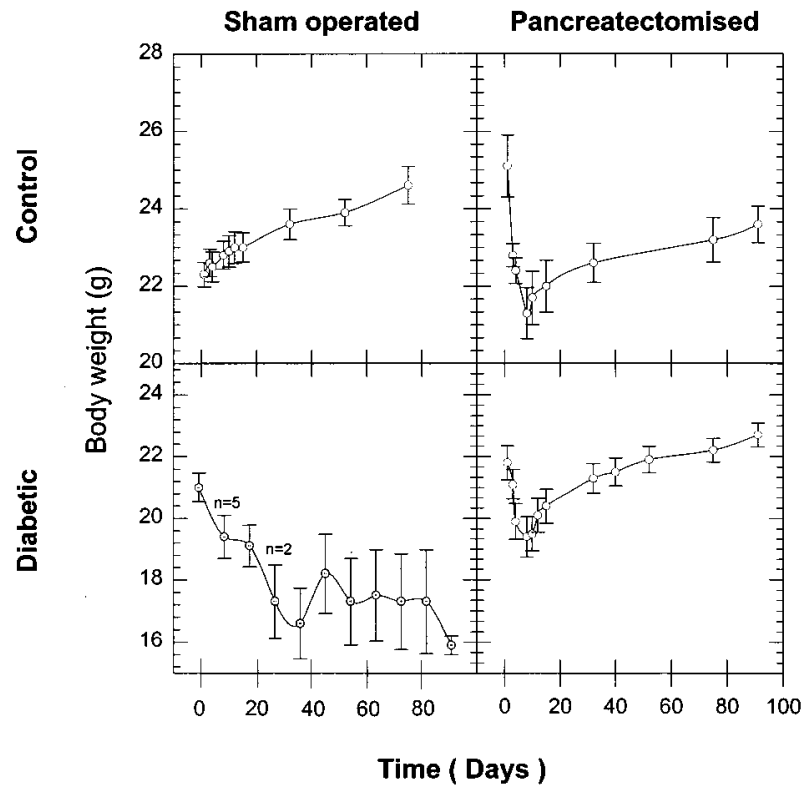

Figure 1 Body weight profiles throughout the period of study in the CS $(n=10), \operatorname{CPx}(n=10)$, DS $(n=9)$ and DPx $(n=15)$ animal groups. Data are expressed as means \pm S.E.M.

CPx animals showed a rapid decrease in body weight during the first 8 days after operation $(25 \cdot 1 \pm 0 \cdot 8$ to $21 \cdot 3 \pm 0.7 \mathrm{~g})$ and then showed a steady weight gain later on $(21 \cdot 3 \pm 0.7$ to $23 \cdot 6 \pm 0.5 \mathrm{~g})$. The DPx group showed a similar trend, except that the initial decline in body weight $(21 \cdot 8 \pm 0 \cdot 5$ to $19 \cdot 4 \pm 0 \cdot 7 \mathrm{~g})$ was followed by a much more rapid weight gain $(19 \cdot 4 \pm 0 \cdot 7$ to $22 \cdot 7 \pm 0 \cdot 4 \mathrm{~g})$ later on (Fig. 1).

The DS group animals had a fasting plasma glucose concentration of $309 \pm 6 \cdot 1 \mathrm{mg} / \mathrm{dl}$ on the day of operation, and maintained hyperglycaemic levels on day 5 $(336 \pm 12 \cdot 6 \mathrm{mg} / \mathrm{dl})$, day $10(331 \pm 14 \cdot 2 \mathrm{mg} / \mathrm{dl})$, day 15 $(326 \pm 25 \cdot 1 \mathrm{mg} / \mathrm{dl})$ and day $20(290 \pm 37 \cdot 7 \mathrm{mg} / \mathrm{dl})$ after the day of operation. In the DS group, only three of nine animals survived the glycaemic stress after 20 days of uncontrolled diabetic status. However, these survivors remained diabetic throughout the period of study (fasting plasma glucose $273 \pm 12 \cdot 8 \mathrm{mg} / \mathrm{dl})$. The CS group animals remained euglycaemic $(97 \cdot 0 \pm 5 \cdot 7$ to $109 \cdot 3 \pm 8 \cdot 1 \mathrm{mg} / \mathrm{dl})$ throughout the period of study. The CPx group animals showed an initial increase in plasma glucose $(91 \cdot 1 \pm 6 \cdot 6$ to $263.8 \pm 13.2 \mathrm{mg} / \mathrm{dl})$ that peaked at the 4 th postoperative day (Fig. 2) and reduced to normal values around the 20th postoperative day. After pancreatectomy, animals in the DPx group similarly showed an initial increase in plasma glucose $(280 \cdot 8 \pm 10 \cdot 9$ to $326 \cdot 1 \pm 14 \cdot 7 \mathrm{mg} / \mathrm{dl})$ that peaked on the 4th postoperative day and stabilised to near-normal values about 15 days after operation $(183 \cdot 1 \pm 8.6 \mathrm{mg} / \mathrm{dl})$. All the animals that were rated as frank diabetic at one time or other were also seen to be positive for glucose

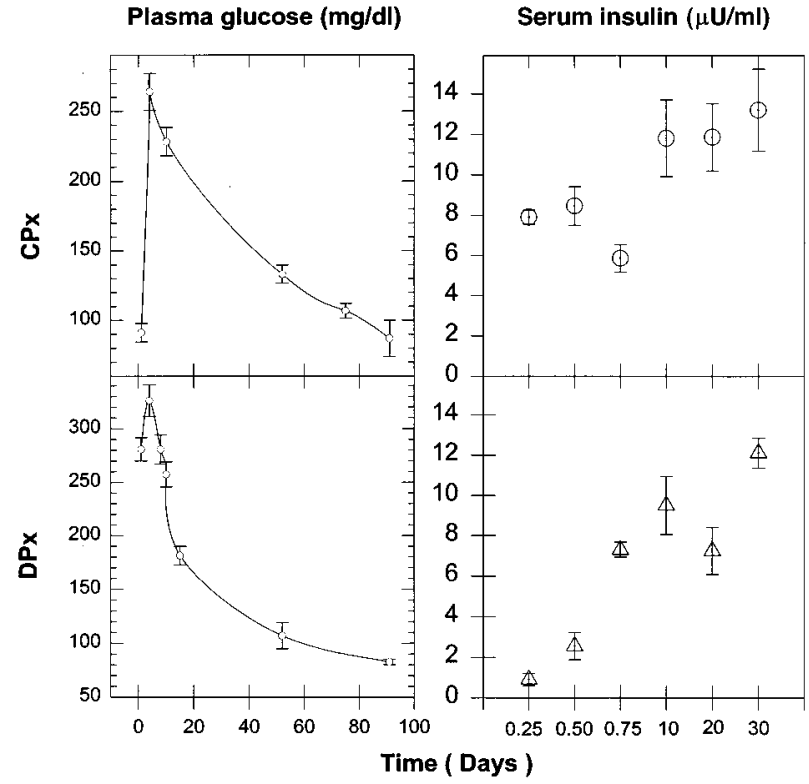

Figure 2 Plasma glucose $(\mathrm{mg} / \mathrm{dl})$ and serum insulin $(\mu \mathrm{U} / \mathrm{ml})$ concentrations in the CPx and DPx animal groups. Data are expressed as means \pm S.E.M. Day 0 represents the day of operation. Postoperative serum insulin values, from $6 \mathrm{~h}$ ( 0.25 days) after pancreatectomy, are from seven animals in each group.

in the urine, whereas the DS group animals had an appreciable amount of ketone in the urine (data not shown).

Serum insulin concentrations in the DPx group were negligible $(0 \cdot 9 \pm 0 \cdot 3 \mu \mathrm{U} / \mathrm{ml}) 6 \mathrm{~h}$ after pancreatectomy, increasing to suboptimal values on day $3(9 \cdot 5 \pm 1 \cdot 4 \mu \mathrm{U} /$ $\mathrm{ml}$ ) and stabilising to normal levels on day 30 $(12 \cdot 1 \pm 0 \cdot 7 \mu \mathrm{U} / \mathrm{ml})$ (Fig. 2). In contrast to this, the serum insulin concentrations of CPx group animals were distinctly higher $(7 \cdot 9 \pm 0 \cdot 3 \mu \mathrm{U} / \mathrm{ml})$ than those of $\mathrm{DPx}$ animals, $6 \mathrm{~h}$ after pancreatectomy, decreasing at $18 \mathrm{~h}$ $(5.9 \pm 0.7 \mu \mathrm{U} / \mathrm{ml})$ and stabilising again by day 30 $(13 \cdot 2 \pm 2 \cdot 0 \mu \mathrm{U} / \mathrm{ml})$. The 6 -h postoperative serum amylase concentrations in $\mathrm{CPx}(50 \cdot 2 \pm 2 \cdot 3 \mathrm{U} / \mathrm{dl})$ and $\mathrm{DPx}$ $(42 \cdot 4 \pm 1.3 \mathrm{U} / \mathrm{dl})$ animals increased rapidly, reaching control values by $24 \mathrm{~h}$ after operation in the CPx $(58 \cdot 4 \pm 0 \cdot 3 \mathrm{U} / \mathrm{dl})$ and the DPx $(56 \cdot 1 \pm 0 \cdot 3 \mathrm{U} / \mathrm{dl})$ groups. Amylase concentrations in these groups varied significantly compared with those in the CS group at $6 \mathrm{~h}$ $(58 \cdot 0 \pm 0 \cdot 4 \mathrm{U} / \mathrm{dl} ; P<0 \cdot 05)$, with no significant differences at $24 \mathrm{~h}$ after operation $(59 \cdot 1 \pm 0 \cdot 6 \mathrm{U} / \mathrm{dl})$.

The pancreatic insulin content was also estimated from a limited number of animals, killed at predefined time points. The regenerating pancreas showed an increasing insulin content from day 5 in both the DPx $(0 \cdot 8 \pm 0 \cdot 1 \mathrm{U} /$ g) and the $\mathrm{CPx}(2.6 \pm 0.5 \mathrm{U} / \mathrm{g} ; P=0.02)$ groups, reaching control values by day $30(4 \cdot 6 \pm 0 \cdot 2 \mathrm{U} / \mathrm{g}$ in group DPx, $4 \cdot 9 \pm 0 \cdot 1 \mathrm{U} / \mathrm{g}$ in group $\mathrm{CPx})$, compared with the insulin content of the CS group $(5 \cdot 1 \pm 0 \cdot 2 \mathrm{U} / \mathrm{g})$ on the 30 th postoperative day. 
(a)

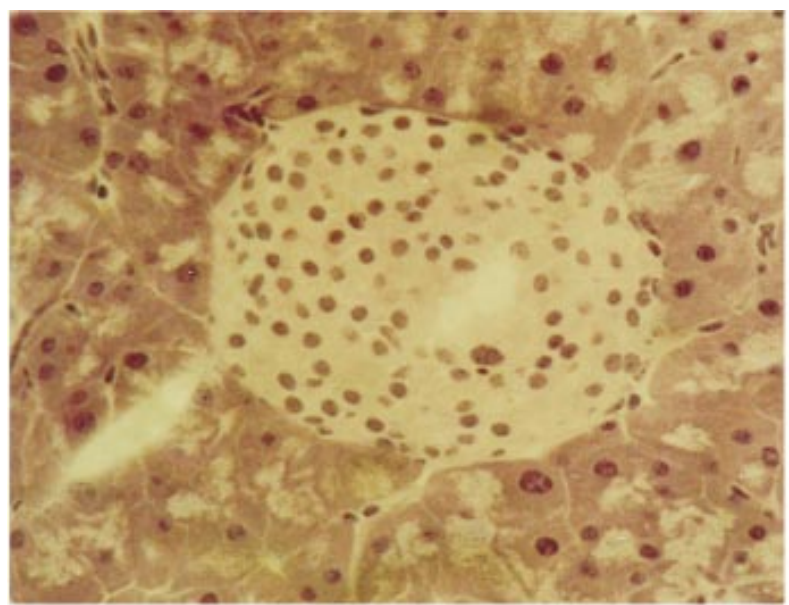

$(C)$

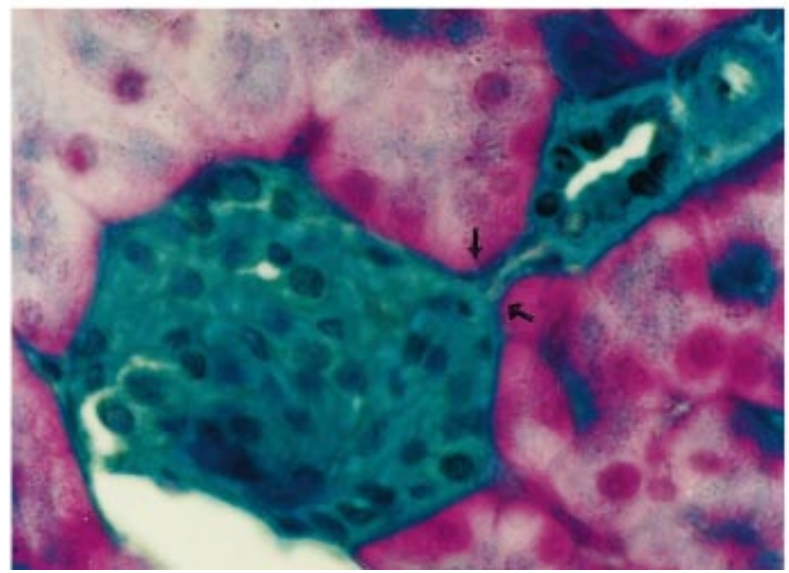

(b)

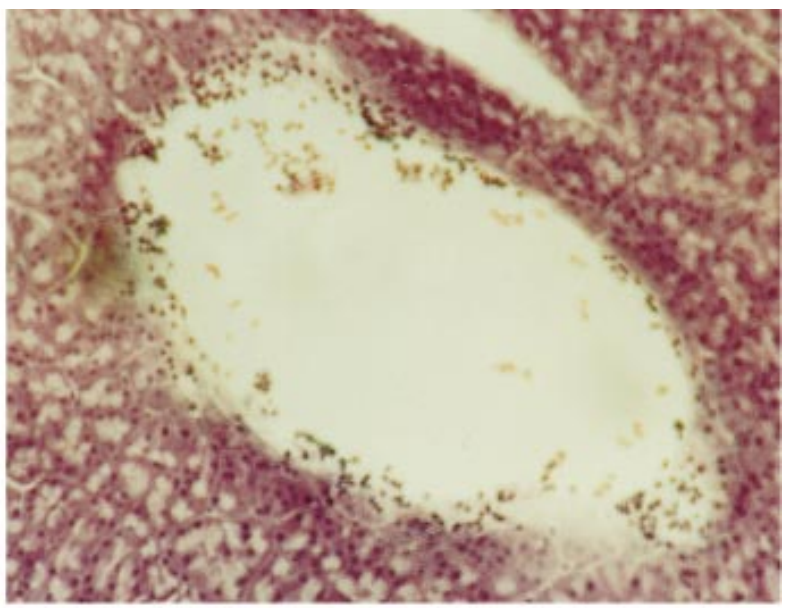

$(d)$

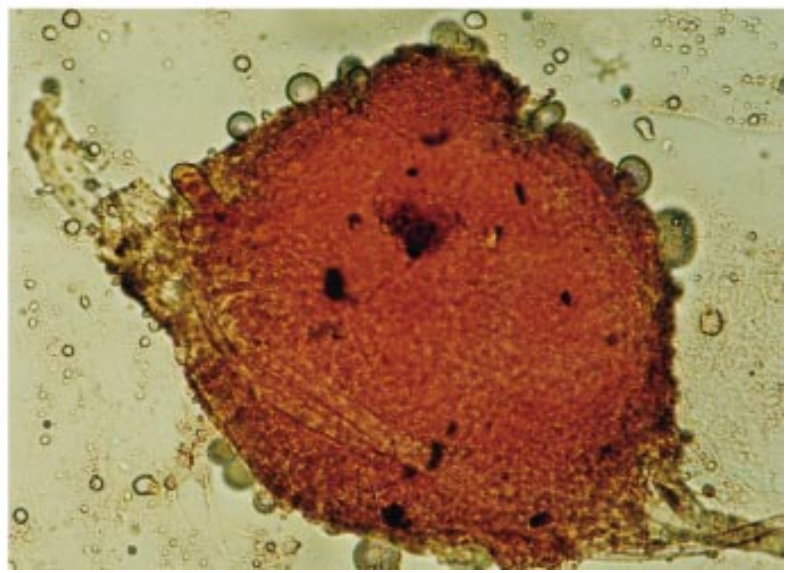

Figure 3 Pancreas from BALB/c mice of: (a) CS group, HE stained and (b) DS group, HE stained. (c) Islets from DPx animal 15 days after the operative procedure; sections stained with HE and light-green. Note the budding of endocrine cells (arrows) from a small, terminal pancreatic ductule $(\times 360)$. (d) An islet isolated from regenerated pancreas of DPx animals, stained with Dithizone $($ Sigma, Poole, Dorset, UK).

The pancreatic sections of DPx and CPx animals showed neoislets budding from the pancreatic duct (Fig. 3). Islets from the CS animals were larger than neoislets from pancreatectomised animals, but showed no connections with the ductal system (Fig. 3). Islets isolated from regenerating pancreas of initially diabetic animals showed a progressive and significant increase in size and number between days $5\left(1227 \cdot 9 \pm 173 \cdot 2 \mu \mathrm{m}^{2}, 135 \cdot 3 \pm 8 \cdot 5\right.$ islets/ pancreas $)$ and $20\left(2473 \cdot 8 \pm 242 \cdot 0 \mu^{2}, \quad 592 \cdot 0 \pm 28 \cdot 1\right.$ islets/pancreas; $P<0.0001$ and $P<0.05$ respectively) after pancreatectomy. However, they remained smaller in size than those isolated from CS animals 20 days after sham operation $\left(9257 \cdot 2 \pm 1198 \cdot 8 \mu \mathrm{m}^{2} ; P<0 \cdot 0001\right)$. Islets isolated from the DPx animals on day 20 did not show any significant differences in islet number from those isolated from the CS group animals $(592 \cdot 0 \pm 28 \cdot 1$ compared with $677 \cdot 0 \pm 34.9$ islets/pancreas). Islet size of $\mathrm{CPx}$ group animals at 5 and 20 days was not significantly different from that of the DPx group animals.

\section{Discussion}

In the present study, we demonstrated that subtotal pancreatectomy in STZ-diabetic mice induced pancreatic nesidioblastosis leading to restoration of normoglycaemic conditions. All the diabetic-pancreatectomised (DPx) mice exhibited reversal of their diabetic state, in contrast to continued diabetes and even death that was observed in the DS group animals.

The first sign of the diabetic status was the characteristic decrease in body weight in the STZ-induced diabetic (DS and DPx) and CPx animal groups. This decline was, however, of a transitory nature in the Px groups and of a 
more permanent nature in the DS group, indicating their inability to compensate for the weight loss. In our mouse model, minimal body weights were obtained around the 8 th postoperative day, followed by a subsequent progressive weight gain later on throughout the period of study. Concomitantly, during this time, the plasma glucose concentrations were also seen to decline towards normoglycaemic values. Immediately after pancreatectomy, a sharp peak indicating an increase in plasma glucose was detected in both the CPx and the DPx groups; however, the $\mathrm{CPx}$ group always maintained a comparatively lower, although diabetic, glucose concentration $(263 \cdot 8 \pm$ $13 \cdot 2 \mathrm{mg} / \mathrm{dl})$ compared with that of the DPx group $(326 \cdot 1 \pm 14 \cdot 6 \mathrm{mg} / \mathrm{dl})$.

These differences could be explained on the basis of the animal models that we used. In rats and mice, the pancreas is diffuse, not well defined as in primates (Scow 1957). These diffuse pancreata are termed mesenteric pancreas, in contrast to the well-defined splenic pancreas. In the $90 \%$ pancreatectomy model of Bonner-Weir et al. (1983), a sufficient $\beta$-cell mass is kept intact to trigger the regenerative process. However, in our diabetic pancreatectomy model, in which injection of STZ preceded pancreatectomy, there was scarcely any residual $\beta$-cell mass left to be triggered, even in the mesenteric pancreas. Hence it is logical to conclude that surgical removal of pancreas in the DPx model triggers only the ductal stem cell population to undergo neogenesis of islets, probably recapitulating ontogeny (Bonner-Weir et al. 1993). The differences in peaking of plasma glucose in the CPx and DPx groups may therefore be attributed to a normal/functional mesenteric pancreas in the CPx animals, which did not encounter any diabetogenic insult from STZ as occurred in the DPx or DS groups.

To investigate further the normalisation of blood glucose and body weight, we estimated the serum insulin concentrations, starting at $6 \mathrm{~h}$ after pancreatectomy. Insulin concentrations in the serum were negligible $(0 \cdot 9 \pm 0.3 \mu \mathrm{U} / \mathrm{ml})$ in the DPx group at $6 \mathrm{~h}$, but slowly increased to stable levels by the 30th day after operation, reflecting the regenerative activity of the endocrine pancreas. In contrast to this, the serum insulin profile (Fig. 2) of the CPx animals was distinctly different $(P<0 \cdot 05)$ for the first $18 \mathrm{~h}$ after operation, although the differences in serum insulin concentrations were not statistically significant beyond $18 \mathrm{~h}$ after pancreatectomy. The initial serum insulin content in the CPx group might reflect release by mesenteric $\beta$-cells as a result of compensatory hypertrophy in response to the sudden load on the mesenteric pancreas after pancreatectomy. The same analogy explains the low insulin concentrations in the DPx animals, in which the mesenteric $\beta$-cells had also been destroyed by the toxic effect of STZ. The serum insulin profile of the DPx animals thus indicates production of insulin exclusively by the regenerating pancreas. In case of the CPx group, there was a decline in serum insulin at $18 \mathrm{~h}$ after pancreatec- tomy, which probably could be attributed to exhaustion of the mesenteric $\beta$-cells as a result of the productive overload after the operative insult. The initial increased serum insulin concentrations in the CPx group can also be ascribed to release of insulin from the mesenteric pancreas in response to a sudden loss of pancreatic $\beta$-cells after pancreatectomy, whereas the insulin concentrations after the 3rd day might be reflecting insulin derived from the regenerating pancreas. However, this requires further investigation.

We also observed an increase in insulin content of the CPx and DPx pancreata compared with that of the diabetic (DS) animal group. The progressive increase in both serum and pancreatic insulin concentrations of the DPx animals is a positive indicator of islet neogenesis as a part of the regenerative process occurring after the operative insult. Our histological data from the DPx mice (Fig. 3), 15 days after pancreatectomy, give evidence of nesidioblastotic activity in the regenerating pancreas, supporting the theory of a ductal origin of islet stem cells (Rosenberg \& Vinik 1992, Rosenberg 1995). It is worth noting, however, that the DS animals exhibited no change in diabetic status. The reversal of diabetes obtained in the present study is comparable to that obtained in the $\mathrm{CPx}$ group and thus is accounted for solely by pancreatectomy. During the regenerative process, a highly significant increase $(P<0 \cdot 0001)$ in islet size was also noted, indicating islet cell replication, growth, or both. Our data thus indicate that, in STZ-diabetic animals, pancreatectomy leads to regeneration of the endocrine pancreas, leading to restoration of the euglycaemic state as reflected in circulating glucose and insulin concentrations, in addition to the histological appearance, size and numbers of islets.

In the case of drug-induced diabetes, there is a selective loss of $\beta$-cells, islets, or both. In the case of pancreatectomy, there is a loss of both the endocrine and the exocrine counterpart, and regeneration of the lost pancreas is seen only after such an event. The presence of islet stem cells in the pancreatic duct has been well documented (Rosenberg \& Vinik 1992, Bonner-Weir et al. 1993, Rosenberg 1995). Our pancreatectomy procedure was based on the requirement to keep the ductal pancreas intact, to induce the stem cells to switch into a regenerative or proliferative phase, and our experimental data indeed demonstrated induction of the expected regenerative process. Our findings do not agree with those of Okamoto (1985) and Yonemura et al. (1984), whose pancreatectomised animals (like the CPx group in our study) exhibited glucosuria during their 3-month follow-up study after $90 \%$ pancreatectomy, but rather our data support the work of Bonner-Weir et al. (1993) and the hypothesis of a ductal origin of islet stem cells (Hellerstrom 1984, Rosenberg \& Vinik 1992, Bonner-Weir et al. 1993). This stem cell population in the pancreatic duct has been extensively studied, but the factor(s) responsible 
for directing stem cells towards pancreatic regeneration remain largely unknown. A vital clue to pancreatic regeneration came from the cellophane-wrap model of Rosenberg \& Vinik (1992), wherein they isolated a soluble polypeptide, ilotropin, from the pancreata of ductobstructed non-diabetic hamsters. This polypeptide was shown to 'cure' almost 60\% of STZ-induced diabetic hamsters when administered i.p. for 6 weeks. Our pancreatectomy studies can therefore be looked upon as presenting a much stronger and highly specific stimulus (compared with duct obstruction) for triggering the regenerative process.

We have also examined the exocrine and endocrine function in terms of serum amylase and insulin respectively, starting from $6 \mathrm{~h}$ after pancreatectomy. Our data are in agreement with those of Brokenbrough et al. (1988), and reveal a strong discordance in the regeneration of exocrine and endocrine tissues, the endocrine growth lagging behind the exocrine development. This lag is very much to be expected, as the genes for regeneration of the endocrine pancreas are expressed largely in the exocrine and ductal pancreas, and not in the endocrine counterpart (Miyaura et al. 1991). The understanding of this very basic process of regeneration in diabetic animals may prove to be a highly potent alternative to the cure of diabetes, and may revolutionise the therapeutic approach to treating the condition. It has also been shown that implantation of a $50 \%$ excess by number of $\beta$-cells in normal rat produced an equivalent decrease in the islet $\beta$-cell mass of the recipient, and was followed by a proportional increase after removal of the implant (Miyaura et al. 1991). The regenerative response thus seems to be proportional to the amount of pancreas removed, as is seen in case of hepatectomy (Michalopoulos \& DeFrances 1997). This clearly indicates that intrinsic factors present within the pancreas somehow 'sense' the islet mass and manage homeostasis of the $\beta$-cell mass in the normal healthy condition. However, although these factors are intrinsic, they can be modulated by extrinsic factors such as diet, pancreatectomy, etc. (Bhonde 1996). As genetic factors are essential, but not sufficient, to cause diabetes, much depends on environmental factors, and the question remains as to what happens to these factors in the diabetic state? Is the diabetic pancreas a 'storehouse' of inhibitory factors that prevent regeneration, and is that the reason for islet neogenesis after removal of diabetic pancreas? The answers to these and many more questions could conveniently be sought by using the diabetic-pancreatectomised mouse model that we are proposing. The model opens up new avenues and dimensions in the emerging field of regenerative biology (Stocum 1997) with reference to diabetic research by triggering the formation of new tissues from old, and by tilting the balance towards regeneration.

\section{Acknowledgements}

The authors wish to thank Professors Claude Remacle and Joseph J Hoet and Dr Brigitte Reussen, WHO Collaborating Centre for Developmental Biology of the Endocrine Pancreas, Université Catholique de Louvain, Louvain-la-Neuve, Belgium for their help, suggestions and critical comments in the initial preparation and revisions of this manuscript. We also wish to thank Dr C S Yajnik, Director, Diabetes Unit, KEM Hospital, Pune for laboratory facilities and helpful criticism, Dr M R Wani, NCCS Pune for his initial guidance in the operative procedures, and Dr G C Mishra, Director, NCCS Pune for providing support throughout the study period. The project was funded by a grant from NCCS, Poona, India and the entire work is a part of the $\mathrm{PhD}$ thesis of $\mathrm{A} \mathrm{A} \mathrm{H}$.

Part of the paper was presented at the AIDSPIT Conference of the EASD at Innsbruck, Austria, January 1998, and an abstract was published in Hormone Metabolic Research, January 1998.

\section{References}

Bhonde RR 1996 Dietary management of pancreatic beta-cell homeostasis and control of diabetes. Medical Hypotheses 46 357-361.

Bonner-Weir S, Trent DF \& Weir GC 1983 Partial pancreatectomy in rat and subsequent defect in glucose-induced insulin release. Journal of Clinical Investigation 71 1544-1553.

Bonner-Weir S, Baxter LA, Schuppin GT \& Smith FE 1993 A second pathway for regeneration of adult exocrine and endocrine pancreas. A possible recapitulation of embryonic development. Diabetes 42 1715-1720.

Brockenbrough JS, Weir GC \& Bonner-Weir S 1988 Discordance of exocrine and endocrine growth after $90 \%$ pancreatectomy in rats. Diabetes 37 232-236.

Gotoh M, Maki T, Kiyoizumi T, Satomi S \& Monaco AP 1985 An improved method for isolation of mouse pancreatic islets. Transplantation 40 437-438.

Hellerstrom C 1984 The life story of the pancreatic $\beta$-cell. Diabetologia 26 393-400.

Jindal RM, Sidner RA, Cummings O, Miller GA \& Filo RS 1995 Proliferation of rat pancreatic ductal-epithelial cells in vitro and in response to partial hepatectomy and pancreatectomy in vivo. Transplantation Proceedings 27 2991-2992.

Michalopoulos GK \& DeFrances MC 1997 Liver regeneration. Science 276 60-66.

Miyaura C, Chen L, Appel M, Alam T, Inman L, Hughes SD, Milburn JL, Unger RH \& Newgard CB 1991 Expression of $\mathrm{reg} / \mathrm{PSP}$, a pancreatic exocrine gene: relationship to changes in islet $\beta$-cell mass. Molecular Endocrinology 5 226-234.

Okamoto H 1985 Molecular basis of experimental diabetes: degeneration, oncogenesis and regeneration of pancreatic B-cells of islet of Langerhans. BioEssays 2 15-21.

Rosenberg L 1995 In vivo cell transformation: neogenesis of beta cells from pancreatic ductal cells. Cell Transplantation 4 371-383.

Rosenberg L \& Vinik AI 1992 Trophic stimulation of the ductularislet cell axis: a new approach to the treatment of diabetes. In Pancreatic Islet Cell Regeneration and Growth, pp 95-105. Ed AI Vinik. New York: Plenum Press.

Scow RO 1957 Total pancreatectomy in the rat: operation, effects and post-operative care. Endocrinology 60 359-367.

Slack JM 1995 Developmental biology of the pancreas. Development 121 1569-1580. 
Stocum DL 1997 New tissues from old. Science 27615.

Swenne I 1983 Effects of aging on the regenerative capacity of pancreatic B-cell of rat. Diabetes 32 14-19.

Tanigawa K, Nakamura S, Kawaguchi M, Xu G, Kin S \& Tamura K 1997 Effect of aging on B-cell function and replication in rat pancreas after 90\% pancreatectomy. Pancreas 15 53-59.

Yonemura Y, Takashima T, Miwa K, Miyazaki I, Yamamoto H \& Okamoto H 1984 Amelioration of diabetes mellitus in partially depancreatized rats by poly (ADP-ribose) synthetase inhibitors evidence of islet $\beta$-cell regeneration. Diabetes 33 401-404.

Received 6 October 1998

Revised manuscript received 28 January 1999 Accepted 1 March 1999 